\title{
The effects of social interaction, exercise, and test stress on positive and negative affect
}

\author{
CURTIS W. MCINTYRE, DAVID WATSON, and ANNE C. CUNNINGHAM \\ Southern Methodist University, Dallas, Texas
}

\begin{abstract}
The effects of social interaction, exercise, and test stress on positive affect (PA) and negative affect (NA) were investigated using the 20 -item positive affect and negative affect schedule (PANAS). Eighteen undergraduate subjects completed a PANAS at the beginning of a 1-week period to establish baseline levels of PA and NA. Three other PANASs were completed within the week by each subject: one after social interaction, one after exercise, and one prior to a stressful test. The resulting PA and NA scores were compared with the baseline PA and NA scores obtained for each subject. Within-subjects analyses of variance and subsequent multiple comparison tests revealed that PA was increased significantly by social interaction and exercise, but not affected by test stress, and that NA was not affected by social interaction and exercise, but was increased significantly by test stress. The implications of these results are discussed.
\end{abstract}

Extensive recent research indicates that two broad factors-positive affect and negative affect-represent the major dimensions of mood (Mayer \& Gaschke, 1988; Watson, 1988b; Watson \& Tellegen, 1985). Positive affect (PA) reflects a person's level of pleasurable engagement with the environment. High PA is a state of enthusiasm, energy, mental alertness, and determination, whereas low PA is best characterized by feelings of lassitude and lethargy. In contrast, negative affect (NA) reflects a person's general level of subjective distress. High NA is an aversive mood state that includes feelings of anger, guilt, fear, tension, sadness, scorn, and disgust, whereas low NA is best characterized by calmness and serenity.

PA and NA are highly distinctive dimensions that are largely independent of one another. Their distinctive characteristics have emerged gradually from studies showing that they are related to fundamentally different classes of variables. For example, variations in PA-but not NA - are broadly related to various indices of social activity and interpersonal satisfaction (Beiser, 1974; Bradburn, 1969; Phillips, 1967; Watson, 1988a). In contrast, perceived stress is highly correlated with NA, but essentially unrelated to PA (Kanner, Coyne, Schaefer, \& Lazarus, 1981; Watson \& Pennebaker, 1989).

Most of the relevant data in the studies cited above were derived from between-subjects analyses. However, in a few recent studies, similar results have been obtained using within-subjects designs in which social activity and stress were correlated with intraindividual mood fluctuations (Clark \& Watson, 1988; Watson, 1988a). In these studies, the effects of exercise and intense physical ac-

Correspondence should be addressed to Curtis W. McIntyre, Department of Psychology, 310 Hyer Hall, Southern Methodist University, Dallas, TX 75275-0442. tivity were also explored, and it was found that they were related more strongly to changes in PA than in NA.

The studies by Clark and Watson (1988) and Watson (1988a) examined mood changes on a daily basis: Subjects completed mood forms once each day and simultaneously reported on several other variables, such as their activities and stress levels. In the present experiment, we extended these findings by studying the immediate, shortterm effects of these variables on PA and NA. The PA and NA scales from the positive affect and negative affect schedule (PANAS; Watson, Clark, \& Tellegen, 1988) was used, first, to establish baseline mood levels for 18 subjects, and then to assess changes from these baseline levels after social interaction, after vigorous exercise, and before a stressful test.

On the basis of previous research, several predictions were made: First, social activity would increase PA but not decrease NA. Second, exercise would increase PA but not NA. Third, the stress of an imminent test would increase NA but not PA.

\section{METHOD}

\section{Subjects}

Eighteen undergraduates ( 9 male and 9 female) served as subjects. Their mean age was 20.6 years.

\section{Measures}

The PANAS (Watson et al., 1988) contains 10-item PA and NA scales. The 20 mood descriptors were selected on the basis of several factor analyses; they are good factor markers of either high PA or high NA. Watson et al. (1988) have reported extensive data demonstrating the reliability and validity of these scales.

The PANAS PA scale consists of the mood descriptors active, alert, attentive, determined, enthusiastic, excited, inspired, interested, proud, and strong. The PANAS NA scale consists of the descriptors afraid, ashamed, distressed, guilty, hostile, irritable, jittery, nervous, scared, and upset. The subjects rated the extent to which they were experiencing each mood descriptor at that moment. These ratings were made according to a 5-point scale: $1=$ very slightly or not at all; $2=$ a little; 
Table 1

Mean Affect Scores

\begin{tabular}{lcccc}
\hline Affect & Baseline & Social Interaction & Exercise & Test Stress \\
\hline Positive & 31.39 & $37.00^{*}$ & $38.33^{*}$ & 31.39 \\
Negative & 17.33 & 13.67 & 13.06 & $25.33^{*}$ \\
\hline
\end{tabular}

*Significantly different from baseline (Dunnett's tests, $p<.05$ ).

$3=$ moderately; 4 = quite $a$ bit $;$ and $5=$ very much. Total NA and PA scores were obtained by summing the ratings, given the 10 relevant mood descriptors. Thus, the possible range of scores for each affect was 10 to 50 .

\section{Design and Procedure}

Each subject completed a PANAS on four separate occasions: baseline, social interaction, exercise, and test stress. The first PANAS was completed at the beginning of the week and provided baseline scores for PA and NA. The other three PANASs were filled out, one at a time, immediately after social interaction (a date, a party, or a meal with friends), after $20 \mathrm{~min}$ of exercise (brisk walking, jogging, swimming, aerobics, or bicycling), and immediately before a stressful test (in psychology). The subjects were allowed 1 week to engage in these three activities.

\section{RESULTS}

The basic data were the PA and NA scores obtained for each subject under each of the four conditions. The mean PA and NA scores are presented in Table 1. Application of separate one-way within-subjects analyses of variance to the PA and NA data revealed significant conditions main effects for both PA $[F(3,51)=5.25, p<$ $.05]$ and NA $[F(3,51)=20.03, p<.05]$. Subsequent Dunnett's tests $(p<.05)$ contrasting the social interaction, exercise, and test stress means with the baseline mean revealed the following: for PA, the social interaction and the exercise means were significantly greater than the baseline mean, but the test stress mean was not; in contrast, for NA, the social interaction and exercise means did not differ significantly from the baseline mean, but the test stress mean was significantly greater than the baseline mean.

\section{DISCUSSION}

Replicating and extending the results of earlier research, the current study shows that social interaction and exercise led to transient increases in PA but not NA, whereas the stress of an imminent test raises NA but not PA. In other words, each of these variables has immediate shortterm effects on either PA or NA, but not on both. These results replicate those obtained from between-subjects analyses (e.g., Beiser, 1974; Bradburn, 1969; Watson, 1988a; Watson \& Pennebaker, 1989) and in studies of daily intraindividual mood fluctuations (Clark \& Watson, 1988; Watson, 1988a). These mood-event relations have emerged consistently in studies in which diverse measures of mood, social activity, stress, and exercise have been used. Clearly, these results are very robust.

More generally, these results help clarify the meaning of the PA and NA mood dimensions. They show that PA represents a state of active and pleasurable engagement with the environment. Thus, physically strenuous activities (e.g., exercise, sports), epicurean activities (e.g., eating, drinking), and psychologically absorbing activities (e.g., intense intellectual discussions) lead to transient elevations in PA (see Clark \& Watson, 1988; Watson, 1988a).
Conversely, PA also acts as a general motivating force for active, pleasure-seeking behavior. For instance, high levels of PA (either naturally occurring or experimentally induced) are associated with an increased preference for social, prosocial, and physically strenuous activities (Cunningham, 1988b; Rossi \& Rossi, 1977; Strickland, Hale, \& Anderson, 1975). Moreover, heightened levels of PA are related to actual increases in social and prosocial behavior (e.g., Cunningham, 1988a; Shaffer \& Smith, 1985). These and similar findings have led to the suggestion that PA reflects "a goal-oriented activation system which involves, and supports, behavioral mastery of the social and work environment" (Depue, Krauss, \& Spoont, 1987, p. 105).

In contrast, NA levels are not affected by the occurrence or nonoccurrence of active, pleasurable experiences. Instead, NA is related to major crises and stressful events involving health problems, evaluation (exams), embarrassment, or failure (see Watson \& Clark, 1984; Watson \& Pennebaker, 1989). However, these crises and stressful events do not affect PA significantly-that is, one can lead an active and interesting life (high PA) even when confronted with considerable stresses and strains (Watson, 1988a; Watson \& Pennebaker, 1989). Clearly, these findings illustrate the distinctive qualities of PA and NA as well as demonstrate the utility of measuring them separately.

\section{REFERENCES}

BEISER, M. (1974). Components and correlates of mental well-being. Journal of Health \& Social Behavior, 15, 320-327.

BRADBURN, N. M. (1969). The structure of psychological well-being. Chicago: Aldine.

Clark, L. A., \& Watson, D. (1988). Mood and the mundane: Relations between daily life events and self-reported mood. Journal of Personality \& Social Psychology, 54, 296-308.

Cunningham, M. R. (1988a). Does happiness mean friendliness? Induced mood and heterosexual self-disclosure. Personality \& Social Psychology Bulletin, 14, 283-297.

Cunningham, M. R. (1988b). What do you do when you're happy or blue? Mood, expectancies, and behavioral interest. Motivation \& Emotion, 12, 309-331.

Depue, R. A., Krauss, S. P., \& Spoont, M. R. (1987). A twodimensional threshold model of seasonal bipolar affective disorder. In D. Magnusson \& A. Ohman (Eds.), Psychopathology: An interactional perspective (pp. 95-123). Orlando, FL: Academic Press.

Kanner, A. D., Coyne, J. C., Schaefer, C., \& Lazarus, R. S. (1981). Comparison of two modes of stress measurement: Daily hassles and uplifts versus major life events. Journal of Behavioral Medicine, 1, 1-39.

MAYER, J. D., \& GASChKE, Y. N. (1988). The experience and metaexperience of mood. Journal of Personality \& Social Psychology, 55, 102-111.

Phillips, D. L. (1967). Social participation and happiness. American Journal of Sociology, 72, 479-488.

Rossi, A. S., \& Rossi, P. E. (1977). Body time and social time: Mood patterns by menstrual cycle phase and day of the week. Social Science Research, 6, 273-308.

ShafFer, D. R., \& SMITH, J. (1985). Effects of preexisting moods on observers' reactions to helpful and nonhelpful models. Motivation \& Emotion, 9, 101-122.

Strickland, B. R., Hale, W. D., \& ANDerson, L. K. (1975). Effect of induced mood states on activity and self-reported affect. Journal of Consulting \& Clinical Psychology, 43, 587.

WATSON, D. (1988a). Intraindividual and interindividual analyses of positive and negative affect: Their relation to health complaints, perceived stress, and daily activities. Journal of Personality \& Social Psychology, 54, 1020-1030.

Watson, D. (1988b). The vicissitudes of mood measurement: Effects of varying descriptors, time frames, and response formats on measures of positive and negative affect. Journal of Personality \& Social Psychology, 55, 128-141.

Watson, D., \& Clark, L. A. (1984). Negative affectivity: The dispo- 
sition to experience aversive emotional states. Psychological Bulletin, 96, 465-490.

Watson, D., Clark, L. A., \& Tellegen, A. (1988). Development and validation of brief measures of positive and negative affect: The PANAS scales. Journal of Personality \& Social Psychology, 54, 1063-1070.

Watson, D., \& Pennebaker, J. W. (1989). Health complaints, stress, and distress: Exploring the central role of negative affectivity. Psychological Review, 96, 234-254.

Watson, D., \& Tellegen, A. (1985). Toward a consensual structure of mood. Psychological Bulletin, 98, 219-235.

(Manuscript received July 20, 1989). 